\title{
Detection of Gene Dosage in Circulating Free Plasma DNA as Biomarker for Lung Cancer
}

\author{
Alba Mayerly Alvarez ${ }^{1}$, Sandra Janneth Perdomo Lara, ${ }^{1,2}$, Diana M. Palacios ${ }^{3,4}$, \\ Edward Fabián Carrillo ${ }^{1,5}$, Luis Gerardo García Herreros ${ }^{3}$, Fidel Camacho Durán ${ }^{3}$, \\ Paulina Ojeda León ${ }^{6}$, Fabio A. Aristizábal ${ }^{1}$
}

${ }^{1}$ Departamento de Farmacia, Facultad de Ciencias, Universidad Nacional de Colombia, Bogotá, Colombia; ${ }^{2}$ Facultad de Odontología; Unidad de Investigación Básica Oral (UIBO), Universidad el Bosque, Bogotá, Colombia; ${ }^{3}$ Departamento de Patología, Fundación Santa Fe de Bogotá (FSFB), Bogotá, Colombia; ${ }^{4}$ Departamento de Patología, Facultad de Medicina, Universidad Nacional de Colombia, Bogotá, Colombia; ${ }^{5}$ Instituto de Investigaciones Biomédicas, Universidad Libre, Cali, Colombia; ${ }^{6}$ Departamento de Patología, Hospital Santa Clara ESE, Bogotá, Colombia.

Email: faaristizabalg@unal.edu.co

Received July $10^{\text {th }}, 2012$; revised August $14^{\text {th }}, 2012$; accepted August $28^{\text {th }}, 2012$

\begin{abstract}
The increase in the number of gene copies at specific loci is a genetic alteration frequently associated with over expression of the related protein in cancer cells. Genes whose dose is consistently augmented in cancer include those involved in cell cycle control, proliferation, apoptosis, and angiogenesis among others. In this study, gene dose of oncogenes MYCL1, MYCN, MYC, EGFR, ERBB2 and AKT2 in DNA obtained from lung tissue and blood plasma, of patients with primary lung cancer was evaluated with respect to normal lung tissue and plasma DNA of healthy individuals, to determine the capacity of these genes to discriminate normal and neoplastic phenotypes. The number of copies of each gene was determined using real-time $(2-\Delta \Delta C T)$. The AKT2 oncogene was found to be amplified frequently in plasma DNA from patients ( $74 \%$ of cases). This marker showed a noticeable ability to discriminate normal and neoplastic phenotypes, with a $76 \%$ to $89 \%$ probability of correctly recognize a plasma sample provided by a lung cancer patient or a healthy individual. For this reason, this detection could be a very useful tool to supplement the existing diagnostic methods in pulmonary cancer.
\end{abstract}

Keywords: Lung Cancer; Gene Amplification; Plasma; EGFR Family; MYC Family

\section{Introduction}

Lung cancer is the cancer with the highest incidence and mortality worldwide. According to statistics from Globocan in 2008, 1.38 million people died from lung cancer, corresponding to $18.2 \%$ of all cancer deaths [1]. This mortality is due in large part because they are diagnosed in advanced stages of the disease, where treatment strategies are limited and the 5-year survival does not exceed $15 \%$ [2]. Therefore, one of the current goals of cancer research is to generate diagnostic methods that allow early detection of disease. The first changes experienced by cells towards a neoplastic phenotype are at the molecular level [3], among them gene amplification is associated with an over expression of the proteins involved. Identifying these changes and molecular markers of cancer can allow for an early diagnosis and personalized treatments that lead to a better prognosis for survival. After identifying a molecular marker of cancer, it is important for the clinical practice to evaluate biological samples obtained non-invasively. Blood plasma, serum, and sputum have been proposed as suitable biological fluids to assess molecular markers [4], since an increase in the amount of free nucleic acids in these fluids have been detected, and it has been shown that the origin of this DNA is mainly from apoptotic and/or necrotic cells derived from tissue that is undergoing carcinogenic transformation [5]. In this study, the amplification status of oncogenes MYC, MYCN, MYCL1, EGFR, ERBB2, and AKT2 was evaluated with respect to the reference gene $\beta$-actin, in DNA obtained from plasma and lung tissue of lung cancer patients and healthy volunteers. Then the amplification state of these genes was assessed in order to verify if these genes could differentiate between a normal and cancerous phenotype, and if plasma was a suitable biological sample to detect molecular tumor characteristics.

The MYC family genes (MYC, MYCN and MYCL1) encode a number of transcription factors involved in multiple cellular functions, including activating DNA 
synthesis and cell cycle progression [6]. The genes EGFR, ERBB2, and AKT2 are involved in important signaling pathways related to cellular functions such as proliferation, apoptosis, and angiogenesis [7].

\section{Materials and Methods}

\subsection{Samples}

A total of 55 samples of blood plasma from patients diagnosed with primary lung cancer (PC) treated in the Hospital Santa Clara and Fundación Santa Fe de Bogotá between 2004-2009 were included. Of these 55 samples of plasma, there were 27 paired samples that included both the plasma sample and paraffin-embedded tumor tissue (T) (Table 1).

A case-control study was conducted with blood samples, using 55 plasmas of healthy volunteers $(\mathrm{PH})$, nonsmokers of the same-sex and age of the cancer patients enrolled in the study. Additionally, 35 samples of normal lung tissue $(\mathrm{N})$, paraffin embedded, supplied by the Department of Pathology, Hospital Santa Clara were included.

\subsection{Collection and Processing of Samples}

Plasma: With the informed consent of the patients, $4 \mathrm{~mL}$ of peripheral blood was collected in EDTA tubes. The sample was centrifuged at $358 \mathrm{~g}$ for 10 minutes, and the plasma was separated into tubes of $1.5 \mathrm{~mL}$ to be further centrifuged at $2700 \mathrm{~g}$ for 10 minutes to eliminate contamination by lymphocytes. The plasma obtained was stored at $-70^{\circ} \mathrm{C}$ before DNA extraction.

Lung tissue: The cases obtained were reviewed by a pathologist to confirm the diagnosis. In each paraffin block, 3 consecutive histological cuts were performed and then stained with H\&E: a histological cut $3 \mu \mathrm{m}$ thick with delineated areas of interest in both neoplastic and normal lung tissue, and two cuts of $10 \mu \mathrm{m}$ for the micro- dissection of the tissue.

\subsection{DNA Extraction}

An aliquot of $200 \mu \mathrm{L}$ of blood plasma or microdissected tissue was incubated at $56^{\circ} \mathrm{C}$ in a lysis buffer $(50 \mathrm{mM}$ Tris HCL, $2 \mathrm{mM}$ calcium acetate $\mathrm{pH} 8.0$ ) and proteinase $\mathrm{K}(1 \mu \mathrm{g} / \mu \mathrm{L})$ (BIOLINE) for 16 hours. DNA extraction was performed using the phenol-chloroform-isoamyl alcohol method and precipitated with ethanol. The DNA quality was assessed with conventional PCR, amplifying a 247-bp Alu sequence, with primers and conditions reported by Umetani et al. [8] and electrophoresis in a 2\% agarose gel. DNA extraction.

\subsection{Determination of the Gene Copy Number}

The number of gene copies in each sample was evaluated with real-time multiplex PCR using Taqman probes. For this, two PCR mixes were optimized and performed, one to amplify EGFR, ERBB2, AKT2 and ACTB (Figure 1), and another one for MYC, MYCN, MYCL1 and ACTB genes (Figure 2). The gene dosage of each oncogene was determined, utilizing the gene ACTB as a reference, with the double-delta $\mathrm{CT}$ relative quantification $(2-\Delta \Delta \mathrm{CT})$ method in duplicate assays, using the kit TaqMan ${ }^{\circledR}$ Fast Universal PCR Master Mix and Applied Biosystem 7500 instruments. The calculations were made following the instructions of this instrument [9]. It was confirmed earlier that the efficiencies of the amplifications for each gene were similar, using the method published by Kenneth J. Livak, et al. [10]. The reactions were made in a final volume of $25 \mu \mathrm{L}$, containing: $1 \times$ Master Mix, 0.04 $\mu \mathrm{M}$ of each primer and $0.375 \mu \mathrm{M}$ of each probe. The PCR program used was: $95^{\circ} \mathrm{C} \times 10$ minutes, 50 cycles $\left(95^{\circ} \mathrm{C} \times 15\right.$ seconds, $61^{\circ} \mathrm{C} \times 1$ minute). Table 2 shows the sequence of primers and probes used. A 2- $\Delta \Delta \mathrm{CT}$ value greater than 2 was considered gene amplification [11].

Table 1. Sequence of primers and Taqman probes used in the multiplex PCRs.

\begin{tabular}{|c|c|c|c|}
\hline GENE & PROBE (5'-3') & RIGHT PRIMER (5'-3') & LEFT PRIMER (5'-3') \\
\hline ERBB2 & $\begin{array}{l}\text { (Tamrra) ATCCGTCCGCCTCAGCCTCCCAAA } \\
\text { (Hex) }\end{array}$ & GTCTTGAACTCCCCACCTCAG & ACAGACGGTACACACTTTTAAAGG \\
\hline EGFR & $\begin{array}{l}\text { (Fam) AACTAACCGCCGCCAGCACCACC } \\
\text { (tamrra) }\end{array}$ & GACCTGGGAGCTGGGAGAAC & ACCTGCCTTTTGCCAACGAG \\
\hline AKT2 & $\begin{array}{l}\text { (Tamrra) ACCACGAGCCACGGAAGCCAGTCA } \\
\text { (rox) }\end{array}$ & AGACCTGGGCTGGTGATGTG & CAGACTGTGGGACCTTTCTCTC \\
\hline MYC & $\begin{array}{l}\text { (Tamrra) ACCAGCAGCAGCAGCAGAGCGA } \\
\text { (rox) }\end{array}$ & TCTACTGCGACGAGGAGGAG & GCAGCAGCTCGAATTTCTTCC \\
\hline MYCN & $\begin{array}{l}\text { (Tamrra) CGCCGCTTCTCCACAGTGACCACG } \\
\text { (hex) }\end{array}$ & AGGAAGATGAAGAGGAAGAAATCG & TGACAGCCTTGGTGTTGGAG \\
\hline MYCL1 & $\begin{array}{l}\text { (Tamrra) ACCTGGAGACACCTGGACACGCCC } \\
\text { (tamrra) }\end{array}$ & CCTAAGAGACCTTCAAGCCAGTG & CCAGATATGGGGCTCATAACACC \\
\hline ACTB & (Tamrra) TTGCCTCCCGCCCGCTCCCG (fam) & CCGTCTTCCCCTCCATCGTG & GGCTCCTGTGCAGAGAAAGC \\
\hline
\end{tabular}


Table 2. Clinical characteristics of patients with lung cancer.

\begin{tabular}{|c|c|c|}
\hline VARIABLE & PLASMA & TUMOR \\
\hline \multicolumn{3}{|l|}{$\operatorname{GENDER}(n . \%)$} \\
\hline Male & $36(65 \%)$ & $19(70 \%)$ \\
\hline Female & $19(35 \%)$ & $8(30 \%)$ \\
\hline$A G E^{a}$ & $60(25.85)$ & $58.6(25.85)$ \\
\hline \multicolumn{3}{|l|}{ TUMOR HISTOLOGY (n) } \\
\hline Preneoplastic lesion & $1(1.8 \%)$ & 0 \\
\hline Carcinoide & $3(5.4 \%)$ & $2(7.4 \%)$ \\
\hline Squamous carcinoma & $15(27 \%)$ & $9(33 \%)$ \\
\hline Adenocarcinoma & $25(45 \%)$ & $11(40.7 \%)$ \\
\hline Adenoid cystic carcinoma & $1(1.8 \%)$ & $1(3.7 \%)$ \\
\hline Small cell anaplastic carcinoma & $2(3.6 \%)$ & $1(3.7 \%)$ \\
\hline Large cell anaplastic carcinoma & $3(5.4 \%)$ & $2(7.4 \%)$ \\
\hline Others $^{b}$ & $5(9 \%)$ & $1(3.7 \%)$ \\
\hline \multicolumn{3}{|l|}{ TUMOR CHARACTERISTICSC } \\
\hline Poorly differentiated & $1(1.8 \%)$ & 0 \\
\hline Moderately differentiated & $3(5.4 \%)$ & $2(7.4 \%)$ \\
\hline Well differentiated & $15(27 \%)$ & $9(33 \%)$ \\
\hline Not specific & $25(45 \%)$ & $11(40.7 \%)$ \\
\hline
\end{tabular}

\subsection{Statistical Analysis}

Statistical analysis was performed with the MedCalc program. The Man-Whitney's test was used to determine differences in the gene copy number between neoplastic and healthy samples, for both the DNA obtained from the plasma and from the paraffin blocks. Box and Whisker Diagrams were made of these results. The potential of each marker to discriminate between a normal and tumoral phenotype was evaluated using ROC curves, with the addition of Excel XLSTAT. To assess whether the observed molecular characteristics found in tumors correlated with those found in plasma, the Spearman test was used and the coefficient of correlation of the paired samples of plasma and tumor tissue was determined. The sensitivity, specificity, positive and negative predictive value of each gene was estimated.

\section{Results}

\subsection{Patients}

This study reported the relative quantification of the oncogenes MYCL1, MYCN, MYC, EGFR, ERBB2 and AKT2 in a group of 55 lung cancer patients. Among them, 36 were men and 19 women, with an average age of 60 years (range $25-85$ ), with any of the following histological types of tumor: neuroendocrine carcinoma (carcinoid tumor), squamous cell carcinoma, adenocarcinoma, adenoid cystic carcinoma, small cell anaplastic carcinoma, large cell anaplastic carcinoma, or those that presented with a preneoplastic lesion (Table 1).

\subsection{Quantification of Gene Dosage Lung Tissue}

The most frequently amplified gene in primary tumors was AKT2 (74\% of the samples), followed by MYCL1 (56\%), MYC (48\%), MYCN (41\%), ERBB2 (19\%) and finally EGFR (11\%). In healthy lung, the amplification frequencies were lower: ERBB2 (11\%), MYCL1 (8\%), EGFR (6\%), AKT2, MYC and MYCN (3\%) (Table 3). The Mann-Whitney's test, used for data analysis, revealed significant differences in the number of copies found in lung cancer and healthy patients for the genes AKT2 $(\mathrm{P}<0.0001)$, MYC $(\mathrm{P}<0.0001)$, MYCN $(\mathrm{P}=$ $0.0006)$ and MYCL1 $(\mathrm{P}=0.0026)$ but not for EGFR $(\mathrm{P}=$ $0.1200)$ and ERBB2 $(\mathrm{P}=0.8983)$ (Figure 1). These differences are apparent in Table 3, where only one sample of healthy lung had a high level of gene amplification for MYCL1, and none of the other genes showed high levels of amplification. In the tumor samples, the results were very different; all the genes except EGFR presented a gene dose greater than 10 .

\subsection{Specificity and Sensitivity of Markers}

In free DNA in plasma from patients with cancer, the AKT2 gene is amplified more frequently (44\%), followed by MYC (31\%), MYCN (29\%), MYCL1 (24\%) and least amplified genes are ERBB2 (22\%) and EGFR $(15 \%)$. These results were similar to those found in the 

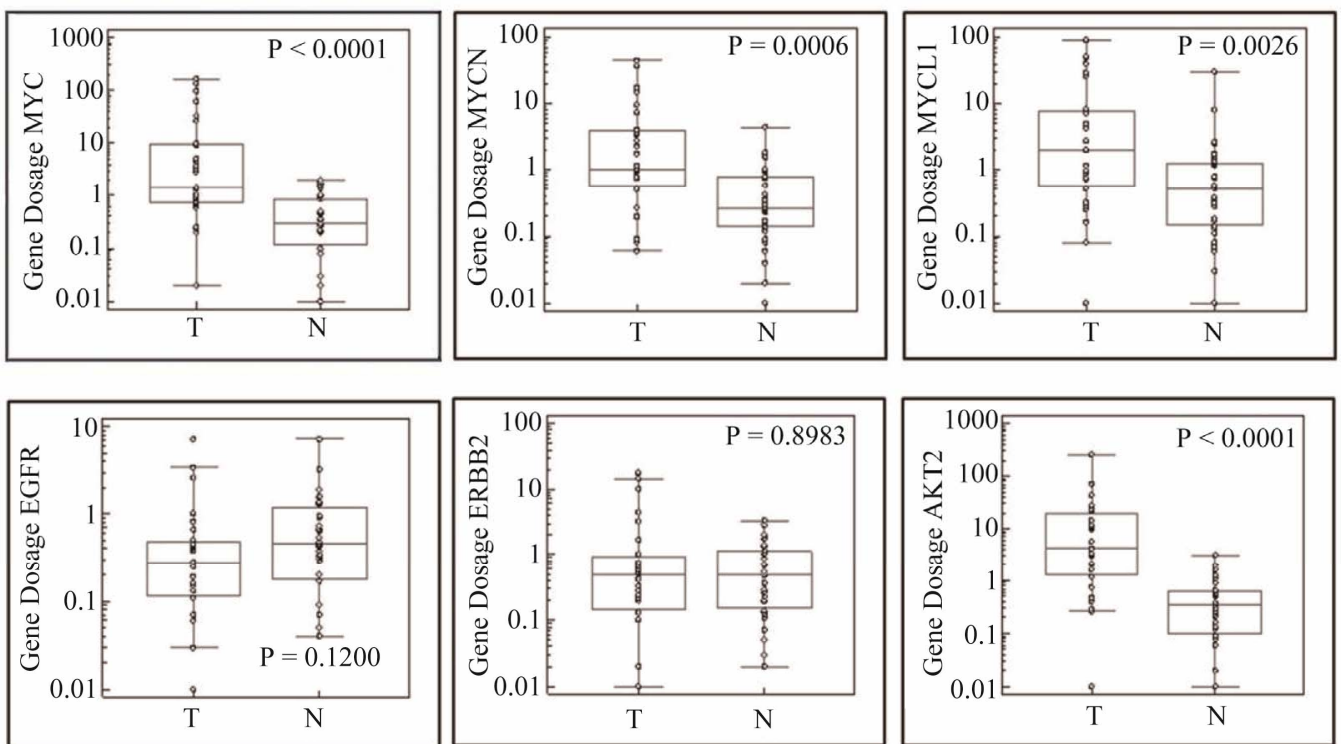

(a)
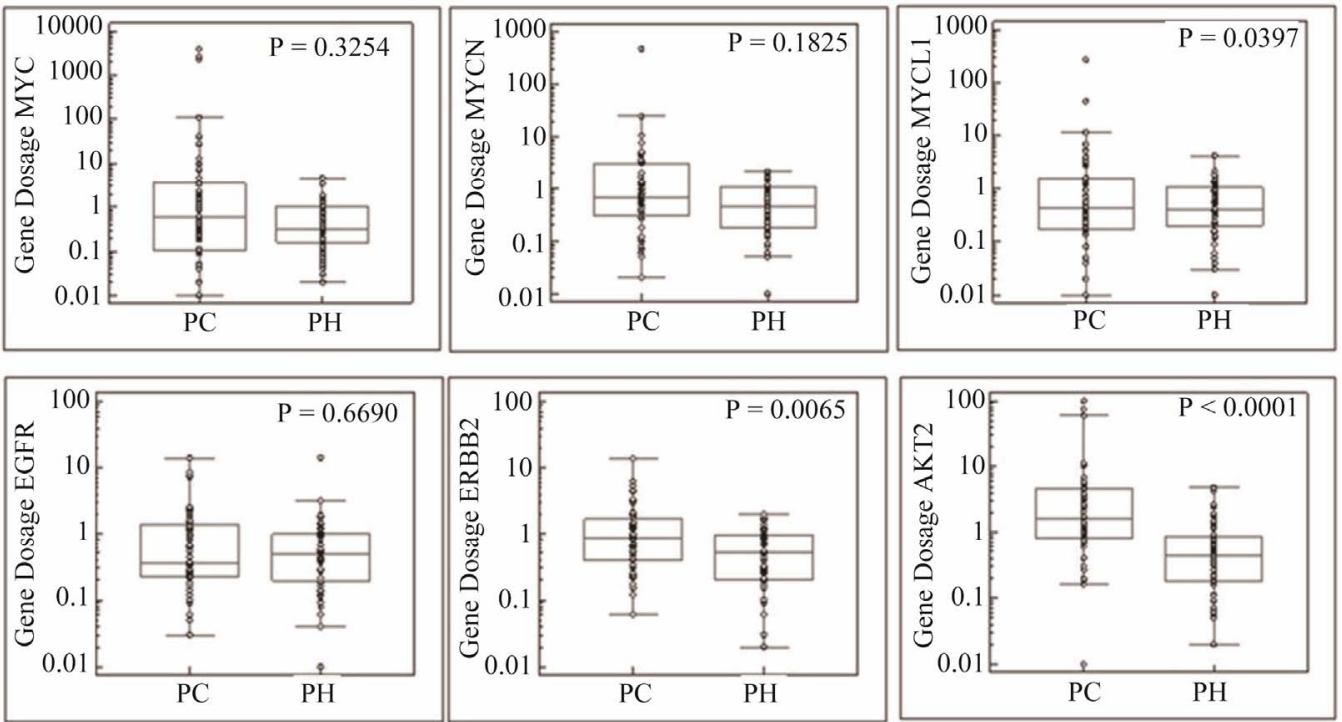

(b)

Figure 1. Gene dosage in lung tissue and plasma. (a) Lung tissue; (b) Plasma.

tumor samples. In the plasma of healthy volunteers, the amplification frequencies were $7 \%$ for AKT2 and MYCN, MYC 5\%, 4\% MYCL1 and EGFR, and 2\% for ERBB2. In comparing the gene dosage of the free DNA in the plasma of cancer patients and healthy volunteers, it was found that the genes that still showed statistically significant differences were: AKT2 $(\mathrm{P}<0.0001)$, and MYCL1 $(\mathrm{P}=0.0397)$, while the ERBB2 gene $(\mathrm{P}=$ $0.0065)$ and the MYC $(\mathrm{P}=0.3254)$ and MYCN $(\mathrm{P}=$ $0.1825)$ genes lost importance, whereas EGFR $(\mathrm{P}=$ $0.6690)$ continued with no statistically significant differences (Figure 1). Table 3 shows that in healthy plasma, the EGFR gene presented a gene dose greater than 10 in only one sample, whereas in cancer plasma all the genes showed a high degree of amplification.

\subsection{Correlation of Paired Plasma and Tumor Samples}

The corresponding values of $2-\Delta \Delta \mathrm{CT}$ to the 27 paired samples are seen in Table 4. To assess whether the gene amplification status found in the tumor can be detected in plasma from the same patient, the Spearman correlation coefficient was estimated. The analysis was done by categorizing the data into two groups. The first group (1) was of the non-amplified genes and the second group (2) was of the amplified genes. This coefficient included values from -1 to 1 , indicating a negative and positive correlation respectively. A value of 0 indicated no corre- 
Lung Tissue

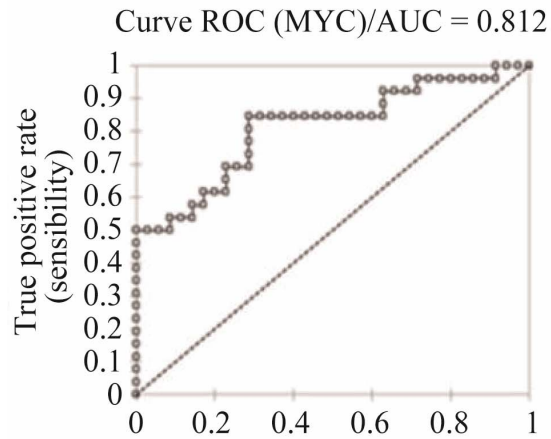

False Positive Rate 1 - specificity

Curve ROC (EGFR)/AUC $=0.363$

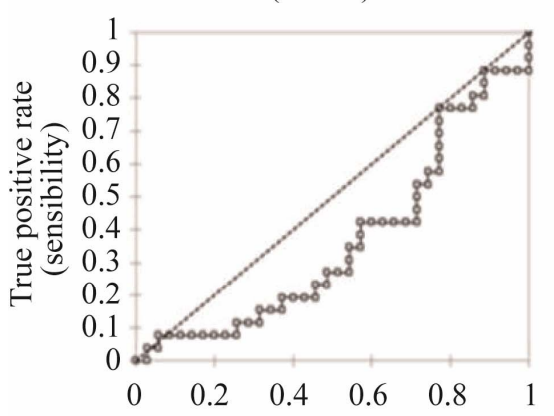

False Positive Rate 1 - specificity

\section{Plasma}

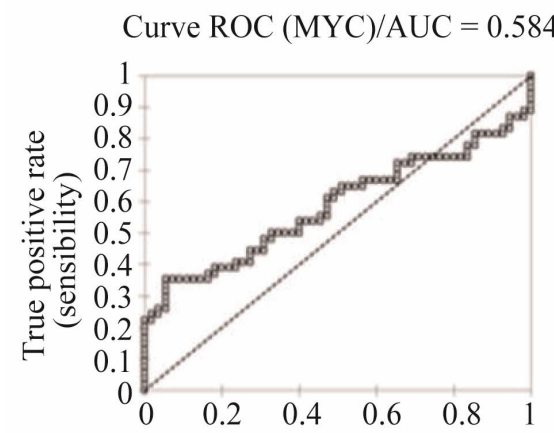

False Positive Rate 1 - specificity

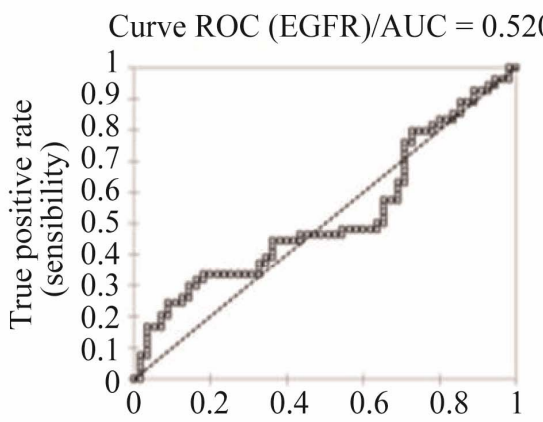

False Positive Rate 1 - specificity
Curve ROC $(\mathrm{MYC}) / \mathrm{AUC}=0.732$

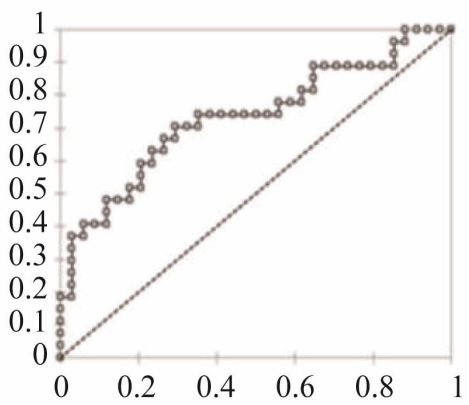

False Positive Rate 1 - specificity

Curve ROC (ERBB2)/AUC $=0.473$

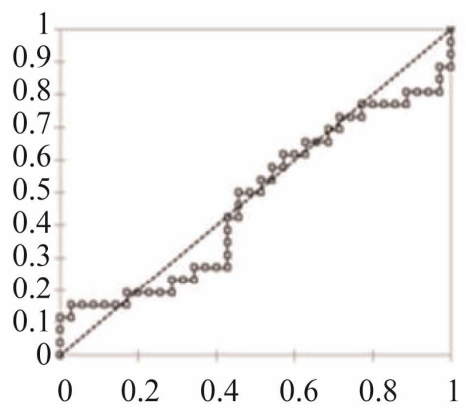

False Positive Rate 1 - specificity

(a)
Curve ROC (MYCL1)/AUC $=0.734$

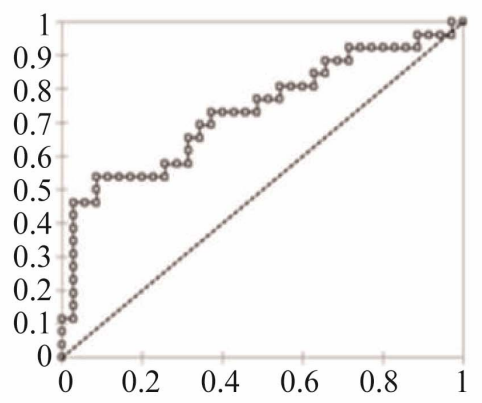

False Positive Rate 1 - specificity

Curve ROC $(\mathrm{AKT}) / \mathrm{AUC}=0.862$

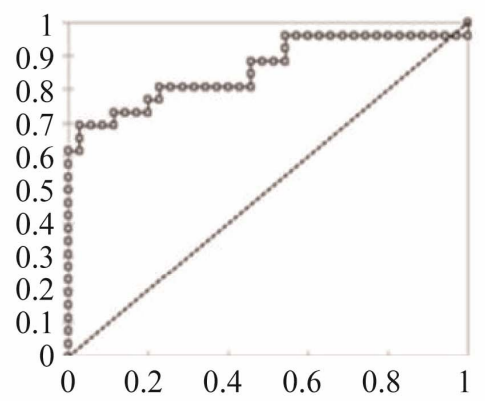

False Positive Rate 1 - specificity
Curve ROC $(\mathrm{MYC}) / \mathrm{AUC}=0.619$

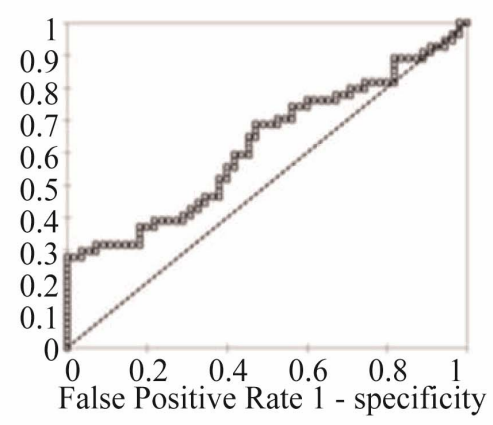

Curve ROC (ERBB2)/AUC $=0.520$

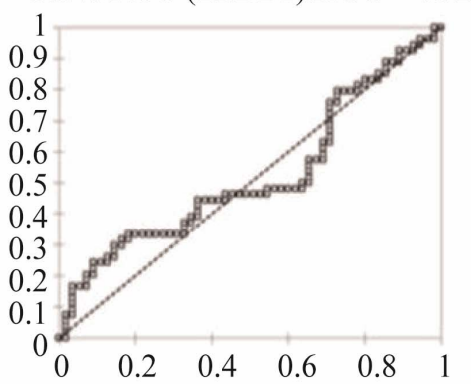

False Positive Rate 1 - specificity

(b)
Curve ROC (MYCL1)/AUC $=0.562$

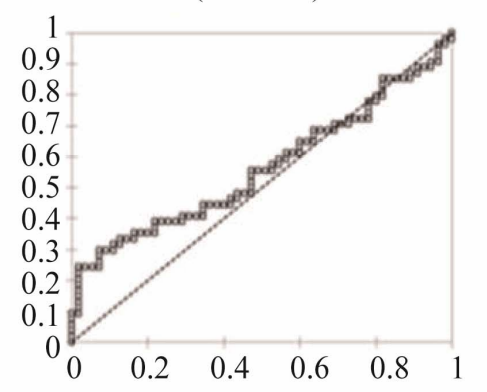

False Positive Rate 1 - specificity

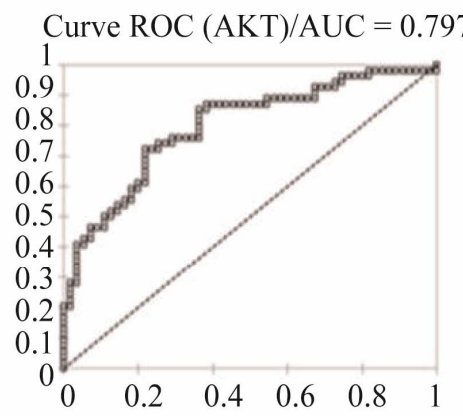

False Positive Rate 1 - specificity

Figure 2. ROC curves by evaluating healthy and cancerous lung tissue and plasma of cancer patients. 
Table 3. Summary of the number of copies found for each oncogene.

\begin{tabular}{|c|c|c|c|c|c|c|}
\hline SAMPLE & GENES & NOT AMPLIFIED & LOW $\geq 2<10$ & HIGH $\geq 10$ & $\begin{array}{c}\text { TOTAL GENES } \\
\text { AMPLIFIED }\end{array}$ & $\begin{array}{c}\text { RANGE OF } \\
\text { AMPLIFICATION }^{\mathrm{a}}\end{array}$ \\
\hline \multirow{6}{*}{$\mathbf{T}$} & MYCL1 & $12(44 \%)$ & $9(33 \%)$ & $6(22 \%)$ & $15(56 \%)$ & 2 to 89 \\
\hline & MYCN & $16(59 \%)$ & $7(26 \%)$ & $4(15 \%)$ & $11(41 \%)$ & 2 to 44 \\
\hline & MYC & $14(52 \%)$ & $7(26 \%)$ & $6(22 \%)$ & $13(48 \%)$ & 3 to 165 \\
\hline & EGFR & $24(89 \%)$ & $3(11 \%)$ & $0(0 \%)$ & $3(11 \%)$ & 3 to 7 \\
\hline & ERBB2 & $22(81 \%)$ & $2(7 \%)$ & $3(11 \%)$ & $5(19 \%)$ & 3 to 18 \\
\hline & AKT2 & $7(26 \%)$ & $9(33 \%)$ & $11(41 \%)$ & $20(74 \%)$ & 2 to 253 \\
\hline \multirow{6}{*}{$\mathbf{N}$} & MYCL1 & $33(92 \%)$ & $2(6 \%)$ & $1(3 \%)$ & $3(8 \%)$ & 2 to 29 \\
\hline & MYCN & $35(97 \%)$ & $1(3 \%)$ & $0(0 \%)$ & $1(3 \%)$ & 4 \\
\hline & MYC & $35(97 \%)$ & $1(3 \%)$ & $0(0 \%)$ & $1(3 \%)$ & 2 \\
\hline & EGFR & $34(94 \%)$ & $2(6 \%)$ & $0(0 \%)$ & $2(6 \%)$ & 3 to 7 \\
\hline & ERBB2 & $32(89 \%)$ & $4(11 \%)$ & $0(0 \%)$ & $4(11 \%)$ & 2 to 3 \\
\hline & AKT2 & $35(97 \%)$ & $1(3 \%)$ & $0(0 \%)$ & $1(3 \%)$ & 3 \\
\hline \multirow{6}{*}{ PC } & MYCL1 & $42(76 \%)$ & $10(18 \%)$ & $3(5 \%)$ & $13(24 \%)$ & 3 to 269 \\
\hline & MYCN & $39(71 \%)$ & $13(24 \%)$ & $3(5 \%)$ & $16(29 \%)$ & 2 to 472 \\
\hline & MYC & $38(69 \%)$ & $9(16 \%)$ & $8(15 \%)$ & $17(31 \%)$ & 2 to 3924 \\
\hline & EGFR & $47(85 \%)$ & $7(13 \%)$ & $1(2 \%)$ & $8(15 \%)$ & 2 to 14 \\
\hline & ERBB2 & $43(78 \%)$ & $11(20 \%)$ & $1(2 \%)$ & $12(22 \%)$ & 2 to 13 \\
\hline & AKT2 & $31(56 \%)$ & $18(33 \%)$ & $6(11 \%)$ & $24(44 \%)$ & 2 to 98 \\
\hline \multirow{6}{*}{ PH } & MYCL1 & 53 (96\%) & $2(4 \%)$ & $0(0 \%)$ & $2(4 \%)$ & 2 to 4 \\
\hline & MYCN & $51(93 \%)$ & $4(7 \%)$ & $0(0 \%)$ & $4(7 \%)$ & 2 \\
\hline & MYC & $52(95 \%)$ & $3(5 \%)$ & $0(0 \%)$ & $3(5 \%)$ & 3 to 5 \\
\hline & EGFR & $53(96 \%)$ & $1(2 \%)$ & $1(2 \%)$ & $2(4 \%)$ & 3 to 13 \\
\hline & ERBB2 & $54(98 \%)$ & $1(2 \%)$ & $0(0 \%)$ & $1(2 \%)$ & 2 \\
\hline & AKT2 & $51(93 \%)$ & $4(7 \%)$ & $0(0 \%)$ & $4(7 \%)$ & 2 to 5 \\
\hline
\end{tabular}

T: Tumoral Tissue; N: Normal Tissue; PC: Plasma Cancer; PH: Plasma Healthy.

lation. For all the genes except EGFR, a positive correlation was observed in the amplification status detected in the plasma-tumor paired samples, with statistically significant $\mathrm{P}$ values (Table 4), which demonstrates the ability of plasma to predict the oncogene amplification status in lung tumors. Table 5 shows the sensitivity and specificity, positive predictive value (PPV) and negative predictive value (NPV) of the six genes to detect the amplification status of the tumor in plasma. The highest sensitivity was observed for the genes ERBB2 (80\%), MYC $(70 \%)$ and AKT $(60 \%)$, values that confirm the Spearman correlations, where the same three genes had positive correlations and the highest statistical significances.

\section{Discussion}

This study reported the gene amplification status of MYCL1, MYCN, MYC, EGFR, ERBB2 and AKT2 in a sample of a Colombian population with lung cancer. The most frequently amplified gene in the primary tumors studied was AKT2 (74\%). This gene is located on chro- mosome 19 (19q13.1 - q13.2), encoding a cytosolic protein that is activated by signaling cascades downstream of growth factor receptors such as EGFR and ERBB2, playing an important role in the physiology of normal and tumoral cells, including the modulation of growth, survival, proliferation and metabolism [12]. Applying Fisher's exact test and a confidence interval of $95 \%$, the amplification of AKT2 was found to be correlated with gender $(P=0.0002)$, of the eight primary tumors from women none showed any amplification, while of the 19 from men, 15 showed amplification of this gene. However, there is no correlation with the histological type or degree of differentiation.

The amplification of AKT2 is highly sensitive and specific (AUC $=0.89$ ) in distinguishing DNA from normal lung and cancer. This sensitivity is retained when assessing the free DNA in plasma of patients and healthy volunteers $(\mathrm{AUC}=0.76)$. These results open the door to fewer invasive diagnostic alternatives than those currently used for the detection of lung cancer. These results 
Table 4. Gene copy number found in the paired samples Tumor/Plasma.

\begin{tabular}{|c|c|c|c|c|c|c|c|c|c|c|c|c|}
\hline \multirow{2}{*}{ Sample No } & \multicolumn{2}{|c|}{ MYCL1 } & \multicolumn{2}{|c|}{ MYCN } & \multicolumn{2}{|c|}{ MYC } & \multicolumn{2}{|c|}{ EGFR } & \multicolumn{2}{|c|}{ ERBB2 } & \multicolumn{2}{|c|}{ AKT2 } \\
\hline & $\mathbf{P C}$ & TC & $\mathbf{P C}$ & TC & PC & $\mathbf{T C}$ & $\mathbf{P C}$ & $\mathbf{T C}$ & $\mathbf{P C}$ & $\mathbf{T C}$ & PC & TC \\
\hline 1 & 0.1 & 39.9 & 0.3 & 44.5 & 0.0 & 0.9 & 1.0 & 3.4 & 6.1 & 4.5 & 1.4 & 3.3 \\
\hline 2 & 0.0 & 0.9 & 0.1 & 3.7 & 0.0 & 0.8 & 0.1 & 0.3 & 1.4 & 0.7 & 0.7 & 4.1 \\
\hline 3 & 0.1 & 2.0 & 0.1 & 9.6 & 0.0 & 0.6 & 1.6 & 0.5 & 3.2 & 3.2 & 1.2 & 2.1 \\
\hline 4 & 0.4 & 0.5 & 0.8 & 0.9 & 0.0 & 0.0 & 0.6 & 0.4 & 1.3 & 0.5 & 1.1 & 0.4 \\
\hline 5 & 0.0 & 0.7 & 0.1 & 1.8 & 0.0 & 0.3 & 0.0 & 0.2 & 0.9 & 0.1 & 4.8 & 10.6 \\
\hline 6 & 0.6 & 5.0 & 0.6 & 1.2 & 28.5 & 0.9 & 2.4 & 2.6 & 2.9 & 14.4 & 59.5 & 253.2 \\
\hline 7 & 4.1 & 29.1 & 3.6 & 2.8 & 27.1 & 131.5 & 2.0 & 0.1 & 0.8 & 0.2 & 5.8 & 23.2 \\
\hline 8 & 2.9 & 4.2 & 3.3 & 1.0 & 2.3 & 32.6 & 0.3 & 0.1 & 0.4 & 0.6 & 0.7 & 0.3 \\
\hline 9 & 0.0 & 4.2 & 0.1 & 4.0 & 0.0 & 1.0 & 1.3 & 0.2 & 4.6 & 0.5 & 1.8 & 1.6 \\
\hline 10 & 6.9 & 7.2 & 5.0 & 14.9 & 12.6 & 3.1 & 0.3 & 7.2 & 1.2 & 17.8 & 5.2 & 72.7 \\
\hline 11 & 0.0 & 0.3 & 0.0 & 0.2 & 0.0 & 2.9 & 1.8 & 0.4 & 5.3 & 10.1 & 6.7 & 17.4 \\
\hline 12 & 3.4 & 4.2 & 1.0 & 0.5 & 9.6 & 4.6 & 0.3 & 0.1 & 1.3 & 0.0 & 1.2 & 0.3 \\
\hline 13 & 3.0 & 8.2 & 4.8 & 3.4 & 0.6 & 26.7 & 0.3 & 0.8 & 0.2 & 0.1 & 0.6 & 0.7 \\
\hline 14 & 5.3 & 2.7 & 7.5 & 7.3 & 0.1 & 0.9 & 1.8 & 0.0 & 3.0 & 0.0 & 1.7 & 0.5 \\
\hline 15 & 0.1 & 1.2 & 0.6 & 2.3 & 1.5 & 1.4 & 0.3 & 0.3 & 1.0 & 1.7 & 2.4 & 11.9 \\
\hline 16 & 0.2 & 26.0 & 0.1 & 0.9 & 3.3 & 3.6 & 1.2 & 0.1 & 0.2 & 0.7 & 3.3 & 14.6 \\
\hline 17 & 0.3 & 2.0 & 0.9 & 1.0 & 1.9 & 0.2 & 0.1 & 0.7 & 0.7 & 0.7 & 2.5 & 10.2 \\
\hline 18 & 0.2 & 89.2 & 0.7 & 36.8 & 3.5 & 60.9 & 0.7 & 0.0 & 0.4 & 0.3 & 0.8 & 5.6 \\
\hline 19 & 0.3 & 0.3 & 0.1 & 0.3 & 0.5 & 0.7 & 0.3 & 0.4 & 0.1 & 0.3 & 1.7 & 1.2 \\
\hline 20 & 0.3 & 0.1 & 0.5 & 0.2 & 0.1 & 0.7 & 0.5 & 0.2 & 0.8 & 0.0 & 0.2 & 0.0 \\
\hline 21 & 0.2 & 0.2 & 1.3 & 0.7 & 4.6 & 9.0 & 2.3 & 0.3 & 1.7 & 0.2 & 4.6 & 4.1 \\
\hline 22 & 0.4 & 50.5 & 3.1 & 17.4 & 2261.1 & 9.9 & 0.3 & 0.4 & 0.5 & 1.0 & 1.0 & 3.0 \\
\hline 23 & 0.7 & 0.8 & 0.6 & 0.8 & 0.4 & 0.2 & 0.1 & 0.1 & 0.3 & 0.0 & 1.3 & 3.1 \\
\hline 24 & 1.3 & 1.0 & 0.4 & 0.9 & 1.8 & 1.3 & 0.1 & 1.0 & 0.4 & 0.4 & 3.1 & 9.8 \\
\hline 25 & 1.4 & 0.2 & 0.5 & 0.1 & 0.2 & 5.2 & 0.4 & 0.2 & 1.0 & 0.2 & 0.9 & 22.2 \\
\hline 26 & 1.6 & 48.7 & 0.7 & 0.1 & 2598.6 & 165.4 & 0.0 & 0.0 & 0.4 & 0.0 & 74.0 & 43.0 \\
\hline \multirow[t]{2}{*}{27} & 1.3 & 0.0 & 0.8 & 0.1 & 3924.1 & 99.3 & 0.2 & 0.4 & 0.5 & 0.6 & 2.7 & 27.2 \\
\hline & \multicolumn{2}{|c|}{$\begin{array}{c}(\text { rho })=0.478 \\
P=0.0117\end{array}$} & \multicolumn{2}{|c|}{$\begin{array}{c}(\text { rho })=0.463 \\
P=0.0149\end{array}$} & \multicolumn{2}{|c|}{$\begin{array}{c}(\text { rho })=0.710 \\
P<0.0001\end{array}$} & \multicolumn{2}{|c|}{$\begin{array}{c}(\text { rho })=0.250 \\
P=0.2085\end{array}$} & \multicolumn{2}{|c|}{$\begin{array}{c}(\mathrm{rho})=0.663 \\
\mathrm{P}=0.0002\end{array}$} & \multicolumn{2}{|c|}{$\begin{array}{c}(\mathrm{rho})=0.529 \\
\mathrm{P}=0.0045\end{array}$} \\
\hline
\end{tabular}

Table 5. Evaluation of plasma to predict the state of amplification of the oncogenes.

\begin{tabular}{cccc}
\hline GENE & SENSITIVITY & SPECIFICITY & PPV \\
\hline MYCL1 & $40(20,64)$ & $100(71,100)$ & $100(100,100)$ \\
MYCN & $45(21,72)$ & $94(69,100)$ & $83(54,100)$ \\
MYC & $77(49,92)$ & $93(66,100)$ & $91(74,100)$ \\
EGFR & $33(6,80)$ & $92(73,99)$ & $33(0,87)$ \\
ERBB2 & $80(36,97)$ & $91(71,98)$ & $67(81,100)$ \\
AKT & $60(39,78)$ & $100(59,100)$ & $95(86,100)$ \\
\hline
\end{tabular}

$\mathrm{PPV}=$ positive predictive value; NPV = negative predictive value. Confidence interval of $95 \%$. 
can be easily applied in clinical practice, as there are systems in place to quantify the gene copy number such as PCR and FISH, among others, and it is a feature that does not change with time and sample processing, bearing in mind that frozen samples from 2004 were studied. However, diagnosing from molecular markers has its limits, such as the small amount of free DNA in the plasma of tumor origin in the early stages of cancer and the failure to provide information about the tumoral location in the lung, for which there could be a complementary diagnostic method utilizing imaging techniques. Another limitation is that in different cancers the same biological signaling pathways are affected, regardless the tumor's location. One example of this phenomenon is amplification of AKT2, reported in lung squamous cell carcinomas [13-15] and other cancer types such as ovarian [1], pancreatic [2] and is over expressed in colorectal cancer [16,17], and lung cancer [18] demonstrating its importance in neoplastic processes. Therefore the use of AKT2 in the detection of lung cancer could be a complementary tool to the diagnostic methods currently being used, such as CT (computed tomography), which allows for a non-invasive localization of the tumor, and more complete diagnosis which can orient the physician in the process of creating a personalized therapy.

One study found that AKT2 gene amplification in some cases of pulmonary squamous cell carcinoma, and its over expression has been observed in lung tumor tissue but not in healthy lung tissue [13]. Currently therapies are being developed and these are directed towards silencing the expression of AKT2 in the NCI-H446 cell line, increasing the chemotherapeutic sensitivity to cisplastin in an effort to partially reverse cisplatin resistance.

The genes EGFR and ERBB2 are tyrosine kinase receptors of the cell surface, and activate important signaling pathways that regulate processes such as proliferation, apoptosis, and angiogenesis [7]. The heterodimerization of these two receptors causes a potent activation of EGFR. In this study, EGFR and ERBB2 were amplified in $11 \%$ and $19 \%$ of the tumors, respectively. Commonly reported for EGFR are amplification frequencies of between $11 \%-40 \%$ and over expression between 40 and $80 \%[19,20]$, and for ERBB2, amplification between 5 and $10 \%$, and overexpression rates between $17 \%-30 \%$. $[12,20,21]$. However, these results show that these genes are also found amplified in healthy lung. Scientific literature reports that patients with amplification of these two genes are more responsive to tyrosine kinase inhibitors such as Gefitinib and Erlotinib. In this population, a strong association was observed between the state of EGFR and ERBB2 amplification, with a Spearman correlation coefficient of $0.74(\mathrm{P}<0.0001)$, suggesting that these genes in the Colombian population would not be useful for diagnosis but for genetic screening, and selection of patients to treat with tyrosine kinase inhibitors in which this type of treatment functions efficiently as there is a strong correlation.

The other three genes studied MYCL1, MYCN, and MYC, encode transcription factors, are important for proliferation, apoptosis and cell differentiation [22,23]. These genes are amplified in primary tumors by $56 \%$, $41 \%$, and $48 \%$ respectively. A correlation has been found between the genes MYCL1 and MYCN (coefficient 0.19 and $\mathrm{P}=0.023$ ). Although the three genes have high sensitivities differentiating healthy lung and lung cancer (AUC > 0.73), in assessing the free DNA in plasma, this sensitivity decreases, as reflected in AUC values between 0.5 and 0.6 . It would be important to evaluate them in other biological samples obtained non-invasively such as sputum.

It can be concluded that the detection of AKT2 gene amplification in plasma is highly sensitive and specific in distinguishing DNA from normal lung and cancer in Colombian population.

Finally, a better articulation of basic research with clinical practice could generate broader results when making correlations with aspects such as tumor stage, metastasis, patient follow-up time, exposure to substances, and family history of cancer. These data are sometimes omitted from the medical history.

\section{REFERENCES}

[1] Applied Biosystems, "Guide to Performing Relative Quantitation of Gene Expression Using Real-Time Quantitative PCR,”2004, pp. 1-70.

[2] J. Bean, C. Brennan, J. Y. Shih, G. Riely, A. Viale, L. Wang, D. Chitale, N. Motoi, J. Szoke, S. Broderick., et al., "MET Amplification Occurs with or without T790M Mutations in EGFR Mutant Lung Tumors with Acquired Resistance to Gefitinib or Erlotinib," Proceedings of the National Academy of Sciences, Vol. 104, No. 52, 2007, pp. 20932-20937.

[3] O. Canoz, M. Ozkan, V. Arsav, O. Er, H. S. Coskun, S. Soyuer and M. Altinbas, "The Role of c-erbB-2 Expression on the Survival of Patients with Small Cell Lung Cancer," Lung, Vol. 184, No. 5, 2006, pp. 267-272. doi:10.1007/s00408-005-2591-y

[4] J. Q. Cheng, A. K. Godwin, A. Bellacosa, T. Taguchi, T. F. Franke, T. C. Hamilton, P. N. Tsichlis and J. R. Testa, "AKT2, a Putative Oncogene Encoding a Member of a Subfamily of Protein-Serine/Threonine Kinases, Is Amplified in Human Ovarian Carcinomas," Proceedings of the National Academy of Sciences, Vol. 89, No. 19, 1992, pp. 9267-9271. doi:10.1073/pnas.89.19.9267

[5] J. Q. Cheng, B. Ruggeri, W. M. Klein, G. Sonoda, D. A. Altomare, D. K. Watson and J. R. Testa, "Amplification of AKT2 in Human Pancreatic Cells and Inhibition of AKT2 Expression and Tumorigenicity by Antisense 
RNA," Proceedings of the National Academy of Sciences, Vol. 93, No. 8, 1996, pp. 3636-3641. doi:10.1073/pnas.93.8.3636

[6] J. A. Crowell and V. E. Steele, "AKT and the Phosphatidylinositol 3-Kinase/AKT Pathway: Important Molecular Targets for Lung Cancer Prevention and Treatment," Journal of The National Cancer Institute, Vol. 95, No. 4, 2003, pp. 252-253. doi:10.1093/jnci/95.4.252

[7] J. Ferlay, H. R. Shin, F. Bray, D. Forman, C. Mathers and D. M. Parkin, "Estimates of Worldwide Burden of Cancer in 2008: GLOBOCAN 2008," International Journal of Cancer, Vol. 127, No. 12, 2010, pp. 2893-2917. doi:10.1002/ijc. 25516

[8] M. E. Garber, O. G. Troyanskaya, K. Schluens, S. Petersen, Z. Thaesler, M. Pacyna-Gengelbach, M. van de Rijn, G. D. Rosen, C. M. Perou, R. I. Whyte, et al., "Diversity of Gene Expression in Adenocarcinoma of the Lung," Proceedings of the National Academy of Sciences, Vol. 98, No. 24, 2001, pp. 13784-13789. doi:10.1073/pnas.241500798

[9] W. C. Gustafson and W. A. Weiss, "Myc Proteins as Therapeutic Targets," Oncogene, Vol. 29, No. 9, 2010, pp. 1249-1259. doi:10.1038/onc.2009.512

[10] R. Herbst, J. Heymach and S. Lippman, "Molecular Origins of Lung Cancer," New England Journal of Medicine, Vol. 359, 2008, pp. 1367-1380. doi:10.1056/NEJMra0802714

[11] F. R. Hirsch, M. Varella-Garcia and F. Cappuzzo, "Predictive Value of EGFR and HER2 Overexpression in AdVanced Non-Small-Cell Lung Cancer," Oncogene, Vol. 28, Suppl. 1, 2009, pp. S32-S37. doi:10.1038/onc.2009.199

[12] C. Huang, L. Yang, Z. Li, J. Yang, J. Zhao, X. Dehui, L. Liu, Q. Wang and T. Song, "Detection of CCND1 Amplification Using Laser Capture Microdissection Coupled with Real-Time Polymerase Chain Reaction in Human Esopha-Geal Squamous Cell Carcinoma," Cancer Genetics and Cytogenetics, Vol. 175, No. 1, 2007, pp. 19-25. doi:10.1016/j.cancergencyto.2007.01.003

[13] X. Lin, A. S. Böhle, P. Dohrmann, I. Leuschner, A. Schulz, B. Kremer and F. Fändrich, "Overexpression of Phosphatidylinositol 3-Kinase in Human Lung Cancer," Langenbeck's Archives of Surgery, Vol. 386, No. 4, 2001, pp. 293-301. doi:10.1007/s004230100203

[14] K. Livakand T. D. Schmittgen, "Analisys of Relative Gene Expression Data Using Real-Time Quantitative PCR and the 2(-Delta Delta C(T)) Method," Methods, Vol. 25, No. 4, 2001, pp. 402-408. doi:10.1006/meth.2001.1262

[15] P. P. Massion, W.-L. Kuo, D. Stokoe, et al., "Genomic Copy Number Analysis of Non-Small Cell Lung Cancer Using Array Comparative Genomic Hybridization: Implications of the Phosphatidylinositol 3-Kinase Pathway," Cancer Research, Vol. 62, No. 13, 2002, pp. 3636-3640.

[16] L. A. G. Ries, D. Melbert, M. Krapcho, et al., "SEER Cancer Statistics Review, 1975-2005," National Cancer Institute, Bethesda, 2008. seer.cancer.gov/csr/1975_2005/2008

[17] P. G. Rychahou, J. Kang, P. Gulhati, H. Q. Doan, L. A. Chen, S. Y. Xiao, D. H. Chung and B. M. Evers, "Akt2 Overexpression Plays a Critical Role in the Establishment of Colorectal Cancer Metastasis," Proceedings of the $\mathrm{Na}$ tional Academy of Sciences, Vol. 105, No. 51, 2008, pp. 20315-30320. doi:10.1073/pnas.0810715105

[18] H. Schwarzenbach, D. Hoon and K. Pantel, "Cell-Free Nucleic Acids as Biomarkers in Cancer Patients," Nature Reviews Cancer, Vol. 11, 2011, pp. 426-437. doi:10.1038/nrc3066

[19] G. Sozzi, D. Conte, M. Leon, R. Ciricione, L. Roz, C. Ratcliffe, E. Roz, N. Cirenei, M. Bellomi, G. Pelosi, et al., "Quantification of Free Circulating DNA as a Diagnostic Marker in Lung Cancer," Journal of Clinical Oncology, Vol. 21, No. 21, 2003, pp. 3902-3908. doi: $10.1200 / \mathrm{JCO} .2003 .02 .006$

[20] N. Umetani, J. Kim, S. Hiramatsu, H. A. Reber, O. J. Hines, A. J. Bilchik and D. S. Hoon, "Increased Integrity of Free Circulating DNA in Sera of Patients with Colorectal or Periampullary Cancer: Direct Quantitative PCR for ALU Repeats," Clinical Chemistry, Vol. 52, No. 6, 2006, pp. 1062-1069. doi:10.1373/clinchem.2006.068577

[21] K. Wang, H. Yamamoto, J. R. Chin, Z. Werb and T. H. $\mathrm{Vu}$, "Epidermal Growth Factor Receptor-Deficient Mice Have Delayed Primary Endochondral Ossification Because of Defective Osteoclast Recruitment," Journal of Biological Chemistry, Vol. 279, No. 51, 2004, pp. 5384853856.

[22] J. Wang, L. J. Miao, Y. M. Wu, Y. J. Wu and X. C. Wang, "Expression of AKT2, Cyclin d1 and MMP-9 and Their Correlation to Clinicopathologic Features of Non-Small Cell Lung Cancer," Cancer, Vol. 25, No. 1, 2006, pp. 6972.

[23] Q. G. Wu, T. T. Cao, Z. Cheng and J. Wang, "Effects of Akt2-siRNA on Chemotherapeutic Sensitivity and Drug Resistance in Human Lung Cancer Cells," National Medical Journal of China, Vol. 91, No. 30, 2011, pp. 2139 2142 . 